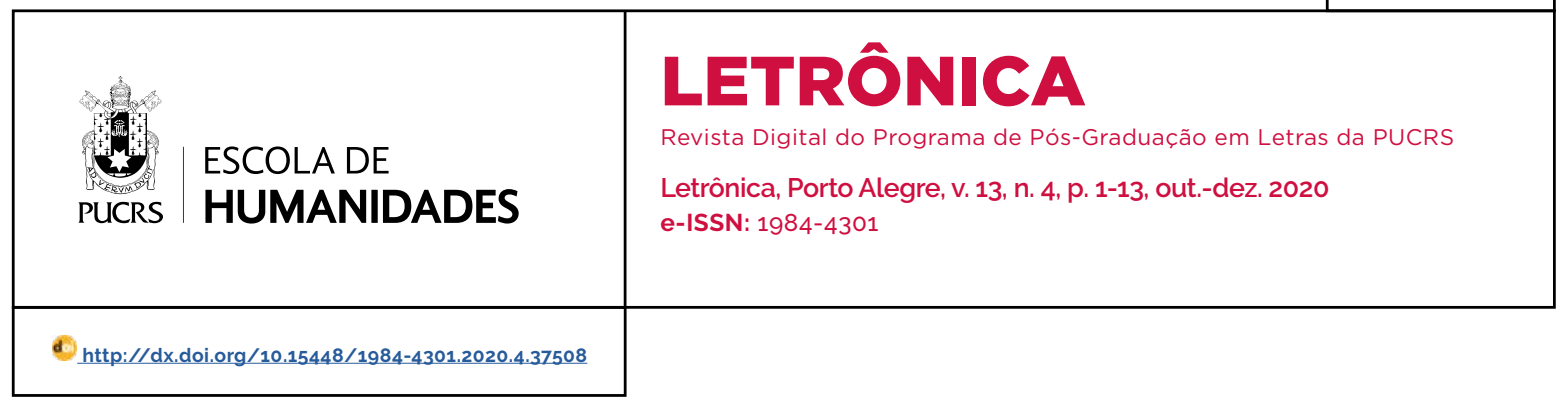

SEÇÃO: ARTIGOS

\title{
A sociolinguística da leitura
}

The sociolinguistics of reading

Raquel Meister Ko.

Freitag $^{1}$

orcid.org/0000-0002-4972-4320

rkofreitag@uol.com.br

Recebido em: 31/3/2020.

Aprovado em: 22/7/2020.

Publicado em: 21/12/2020.
Resumo: Este texto apresenta contribuições da Sociolinguística para a leitura, a partir da observação da leitura em voz alta em sala de aula. Assumindo que a consciência sociolinguística pode ser preditora de sucesso na leitura, apresentamos panoramicamente modelos de leitura e as pistas de superfície de natureza sociolinguistica que permitem inferir niveis de leitura, considerando a dimensão do reconhecimento de palavras e da compreensão linguística. Este referencial subsidia um diagnóstico que o professor pode realizar em sala de aula e direcionar ações para o aprimoramento das habilidades de leitura, mesmo fora do periodo de aprendizado inicial.

Palavras-chave: Sociolinguística. Consciência sociolinguistica. Reconhecimento de palavras. Compreensão linguística.

Abstract: This paper presents contributions from Sociolinguistics to reading, based on the observation of reading aloud. By the assumption that the sociolinguistic awareness can be a predictor of the success in reading, the paper present in a broad sense models of reading and the surface sociolinguistic features that allow to infer levels of reading, considering the word recognition and language comprehension. This approach subsides a diagnosis which teachers can make at classroom and it can goal actions to improve reading skills, even out of initial reading time.

Keywords: Sociolinguistics. Sociolinguistic awareness. Word recognition. Linguistic comprehension.

\section{Introdução}

Ao lidar com a relação entre língua e sociedade, a Sociolinguística é uma área de interface socialmente engajada por excelência. No campo da leitura, nos Estados Unidos, foi a abordagem sociolinguística para a descrição dos padrões do inglês afro-americano, com o reconhecimento da sua sistematicidade, e a aplicação desses resultados que possibilitou ações como a conscientização dos professores de séries iniciais para a diferença e a adoção de abordagens pedagógicas sensiveis às diferenças dialetais, de modo a desfazer mitos e reduzir assimetrias no sistema educacional (WOLFRAM, 1970; LABOV, 1972a; NICHOLS, 1977; BARNITZ, 1980). No cenário brasileiro, conhecimentos dos principios do sistema alfabético do português e das matizes sociolinguísticas do português brasileiro, traduzidas por Bortoni-Ricardo (2004) em três contínuos (oralidade-letramento, monitoramento estilístico e rural-urbano), ou no bidialetalismo funcional de Lemle (1978), são aportes sociolinguisticos à alfabetização, entendida aqui como aprendizagem inicial da leitura e da escrita, e que subsidiam o desenvolvimento de materiais didáti- 
cos sensiveis à variação (MOLLICA; LOUREIRO, 2008), com aplicação nas séries iniciais. Apesar desses aportes, estamos falhando na formação de leitores, com assimetrias nas séries iniciais e que se agravam no segundo ciclo do ensino fundamental. Precisamos, então, de uma receita para "trocar o pneu com o carro andando": não só corrigir as assimetrias de leitura no segundo ciclo, como também ampliar as habilidades.

O objetivo deste texto não é apresentar a solução, mas pontuar aspectos em que a Sociolinguística pode contribuir para a tarefa, particularmente um campo de estudos recente, o do processamento sociolinguístico. Como ponto de partida, tomamos uma atividade relativamente simples de ser realizada na sala de aula: a leitura em voz alta. Assumindo que a sensibilidade sociolinguística pode ser preditora de sucesso na leitura (FREITAG; SÁ, 2019), a partir da leitura em voz alta, apresentamos panoramicamente modelos de leitura (dupla rota, reconhecimento da palavra visual, fases do desenvolvimento da leitura de palavras visão simples da leitura e modelo de cordas) e as pistas de superficie de natureza sociolinguistica que permitem inferir niveis de leitura a partir de cada um destes modelos. Assim, esperamos contribuir para que os professores possam identificar dificuldades na situação de sala de aula, o que pode ajudar no planejamento de atividades especificas para a correção das assimetrias.

\section{Leitura na sala de aula}

Lemos sempre com um propósito: notícias, seja em suportes físicos de jornais impressos ou digitais, enviados por mensagens de celular, para nos informar sobre o mundo em nossa volta, rótulos de produtos para identificar seus componentes e prazos de validade, manuais para poder operar equipamentos, mensagens e e-mails para interagir com as pessoas, formulários para inserir as informações solicitadas, romances e contos para nos distrair e nos dar prazer estético. Essas leituras são, geralmente, feitas em silêncio, a não ser quando queremos compartilhar trechos com pessoas ao nosso redor. O propósito da leitura nos leva a uma questão: qual é a relação da leitura em sala de aula com as atividades da vida cotidiana? Mais especificamente, a leitura em sala de aula é usada para construir conhecimento, para promover interação, para experiência estética, é pretexto para aprender esse ou aquele ponto gramatical ou ainda para treinar pronúncia?

Em uma perspectiva psicolinguística, como a apresentada por Morais (2013), em Criar leitores: para professores e educadores, a atividade de leitura é um processo de construção de significados que envolve a habilidade de processar as informações registradas no papel ou em uma tela (processo bottom-up) e o conhecimento de mundo que o leitor aciona para compreender um texto (processo top-down). Esta concepção de leitura parte de três premissas: a) a decodificação precede a compreensão; b) a leitura não é processo natural, é tecnologia; e c) tecnologia precisa de instrução.

Ler requer uma habilidade especifica: a habilidade de identificação das palavras escritas, e essa habilidade é especifica da leitura, quer dizer, adquire-se durante o processo de aprendizagem da leitura e só serve para a leitura.

Ainda conforme Morais (2013), as habilidades distinguem-se das capacidades mentais por não serem adquiridas naturalmente, por terem de ser aprendidas. Isto é, elas geralmente requerem alguma instrução e um exercício prolongado, e formam-se pela aplicação de determinadas capacidades a um certo tipo de objeto.

No caso que nos interessa, o material é a escrita, e o aprendiz recorre às suas capacidades de percepção visual, de linguagem, de atenção e de memória para desenvolver os mecanismos que asseguram a identificação das palavras escritas.

É o conjunto desses mecanismos que designamos pela expressão "habilidades de identificação das palavras escritas". Ler, no sentido de usar essa habilidade de identificação das palavras escritas, requer, portanto, uma "técnica". E é essa técnica que as crianças que aprendem a ler têm de adquirir, além de precisarem desenvolver as capacidades cognitivas e os conhecimentos linguísticos que thes permitem ler com compreensão.

$\mathrm{O}$ que a escola tem feito? Ao entrarem no se- 
gundo ciclo do fundamental, acreditamos que os alunos já chegam proficientes no nivel bottom-up (processamento da leitura) e queremos formar leitores críticos, mas que sequer conseguem decodificar uma sequência de letras. $O$ argumento para o foco na formação dos "leitores críticos" é que ler é mais que decodificar.... ${ }^{2} \mathrm{~A}$ abordagem de leitura defendida aqui não é dissonante deste argumento; ao contrário, é preciso decodificar, pois para o leitor exercer a sua criticidade, precisa ter demanda cognitiva disponivel para acessar outros significados, realizar inferências, tecer comparações. Para isso, o processo de decodificação no leitor proficiente precisa ser automatizado. O trabalho com a consciência linguística para o aprimoramento de estratégias de leitura no português brasileiro (FLÔRES, 2018; BARETTA; SANTOS; BORGES, 2019) funciona e dá resultados, mas os alunos precisam ter automaticidade na decodificação.

Mas o que fazer com o aluno que chegou no $5^{\circ}$ ano e ainda não é fluente, não tem automaticidade na leitura? A assimetria entre o que se espera de habilidade de leitura e o que os alunos efetivamente conseguem realizar ao final do ciclo de aprendizagem inicial é sistematicamente evocada pelos resultados das avaliações oficiais, como a Avaliação Nacional da Alfabetização (ANA). E a defasagem é ainda mais assimétrica na escola pública (ALMEIDA; FREITAG, 2012; CORSO; SPERB; SALLES, 2013; MACHADO; FREITAG, 2019). Se os alunos chegam ao fundamental maior sem terem automatizado o processo de decodificação, o que fazer? Será que os alunos sabem mesmo ler? Esse é o cenário de trocar o pneu com o carro andando. Para tentar fazer isso, nos apoiamos em estudos que evidenciam a relação entre a fluência e a compreensão em leitura (CORSO; SALLES, 2009; MACHADO; FREITAG, 2019) e defendemos o uso da leitura em voz alta como estratégia de treinamento para a automaticidade e para a identificação das dificuldades dos alunos com atenção às pistas de compreensão pelo professor durante as práticas de sala de aula.

\section{Por que ler em voz alta?}

A leitura silenciosa é uma habilidade relativamente recente na sociedade ocidental (SAENGER, 1997). Crianças começam a ler em voz alta e depois passam para a leitura silenciosa.

A leitura silenciosa é muito mais rápida do que em voz alta (KOMENO et al., 2015), e as pessoas lembram mais depois de leitura silenciosa do que depois de leitura em voz alta. Uma vez aprendida, torna-se uma poderosa habilidade, porque a leitura é automatizada.

No entanto, a leitura silenciosa não é baseada puramente no estímulo visual: há as experiências de quem ouve uma "voz interior" quando está lendo silenciosamente. A leitura silenciosa emula a busca fonológica na memória de trabalho para a desconversão grafo-fonêmica. A leitura em voz alta foi a base dos primeiros estudos para teorias sobre leitura, como o modelo de dupla rota (COLHTEART, 2013). É uma abordagem que pode ser implementada em sala de aula. Acompanhar a leitura em voz alta permite identificar problemas de aprendizagem inicial da leitura, pois a capacidade de ler palavras de forma rápida, precisa e sem esforço é fundamental para a compreensão da leitura e se os processos envolvidos no reconhecimento individual de palavras funcionam adequadamente, a leitura é fluente (PIKULSKI; CHARD, 2005: RASINSKI, 2006; KIM et al., 2010; PAIGE et al., 2014; BASSO, et al., 2019). Para isso, precisamos de modelos de leitura que deem suporte à fluência.

\section{Modelos de leitura}

Há diferentes modelos para explicar como ocorre a leitura, ancorados em diferentes paradigmas e partindo de diferentes concepções de linguagem. Na batalha dos métodos de alfabetização, a diversidade é preferivel ao dogma, já que nenhum modelo se constitui como o modelo correto ou a explicação infalivel. Assim, a escolha dos modelos de leitura que serão apresentados a seguir também parte de uma concepção de linguagem e de um paradigma; não significa que estes modelos são melhores ou superiores; 
apenas que permitem integrar o conhecimento sociolinguístico ao processo de leitura.

A leitura de um sistema de escrita alfabético pode ocorrer por meio de um processo de reconhecimento visual direto (rota lexical) ou por um processo envolvendo mediação fonológica (rota

Figura 1 - Modelo de dupla rota fonológica). A abordagem de leitura que reconhece duas rotas possiveis é conhecida como Modelo de Leitura de Dupla Rota (COLTHEART et al., 1993; COLTHEART; RASTLE, 1994; COLTHEART et al., 2001; COLTHEART, 2013), conforme a Figura 1.

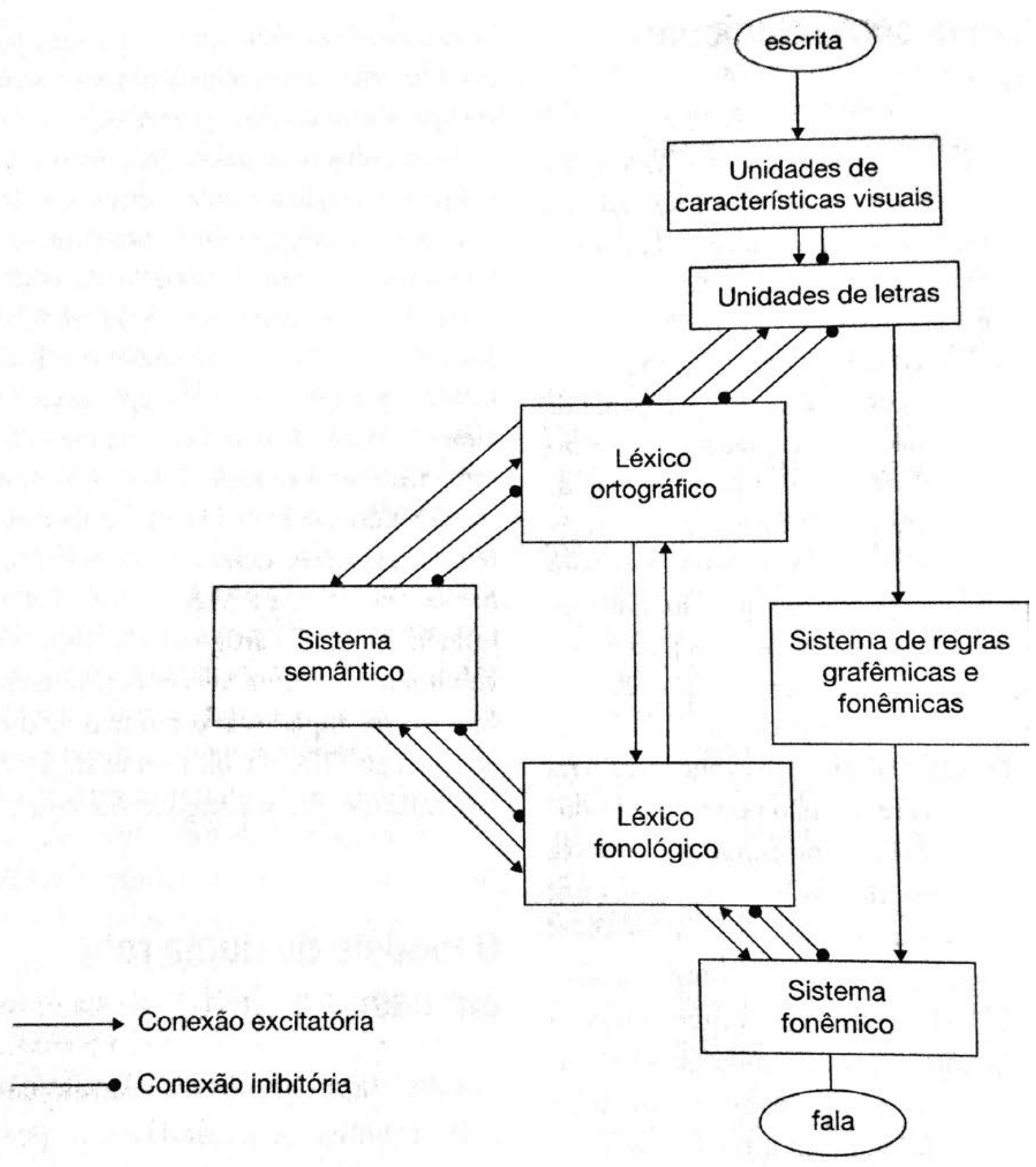

Fonte: Coltheart (2013, p. 30).

Ambas as rotas de leitura iniciam com o sistema de análise visual, que tem a função de identificar as letras, sua posição na palavra e agrupá-las. A rota fonológica é a única possivel 
para ler palavras novas ou raras na ortografia regular, e neologismos. Nessa rota, primeiro ocorre a decodificação das letras, depois a procura de uma possivel pronúncia e depois o sentido. Já a rota lexical é utilizada para as palavras frequentes e indispensável para as palavras irregulares. Leitores que usam preferencialmente a rota lexical têm mais facilidade na leitura de palavras irregulares do que na de pseudopalavras. Por outro lado, leitores que usam preferencialmente a rota fonológica têm maior facilidade na leitura de palavras regulares e pseudopalavras do que nas de palavras irregulares.

O sistema de regras obedece aos princípios do sistema alfabético, ou seja, ao entendimento de que a sequência de letras em uma palavra escrita representa a sequência de sons (fonemas) na palavra falada. Após ativá-lo, o aprendiz precisa construir seus mapas ortográficos, estabelecendo conexões entre letras e sons de modo a ligar a grafia, a pronúncia e o significado das palavras na memória (EHRI, 2014). Assim, mapas ortográficos formam conexões entre as palavras lidas e padrões de sons. Essas conexões são retidas na memória e constituem as palavras visuais (sight words).

Ehri enfatiza a importância das palavras visuais para a proficiência em leitura.

\begin{abstract}
Palavras visuais são palavras que os leitores leram com precisão em ocasiões anteriores. Eles leem as palavras lembrando-se de como as leram anteriormente. O termo "visual" indica que a visão da palavra ativa essa palavra na memória, incluindo informações sobre sua ortografia, pronúncia, papel típico nas sentenças e significado (EHRI, 1998, p. 12).
\end{abstract}

As palavras visuais são lidas como unidades inteiras sem pausas entre os sons; são ativadas na rota lexical no modelo de dupla rota. Antes de chegar a esse ponto, o aprendiz passa por fases do desenvolvimento da leitura de palavras (pré-alfabética -> alfabética inicial -> alfabética avançada -> consolidada (EHRI, 1995)); mas em caso de leitores que já passaram pelo aprendizado inicial, também podem ser verificados estágios do reconhecimento das palavras (SAMUELS, 2002):
1. Não acurado
2. Acurado mas não automático
3. Acurado e automático

Figura 2 - Estágios de reconhecimento da palavra

\section{0 cachorro pequeno latiu para o gato grande.}

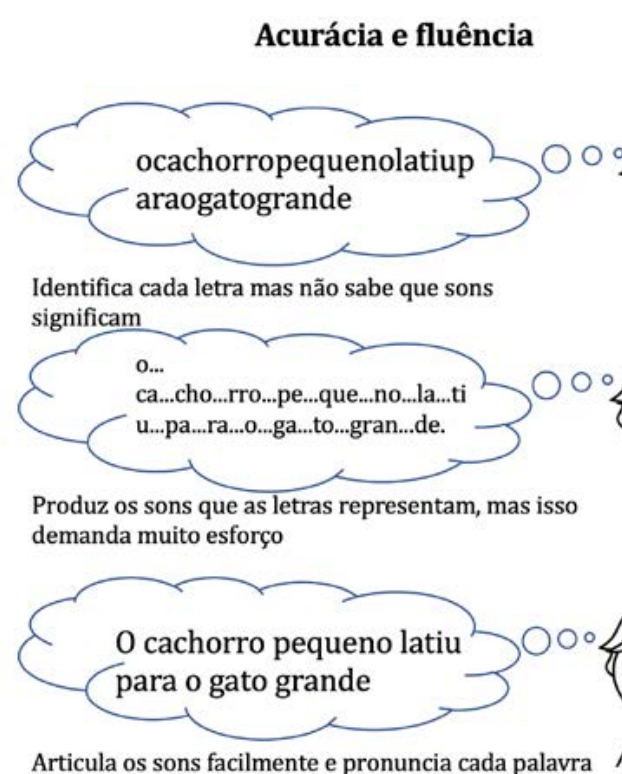

Articula os sons facilmente e pronuncia cada palavra

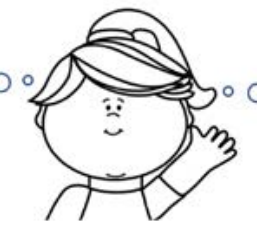

Significado
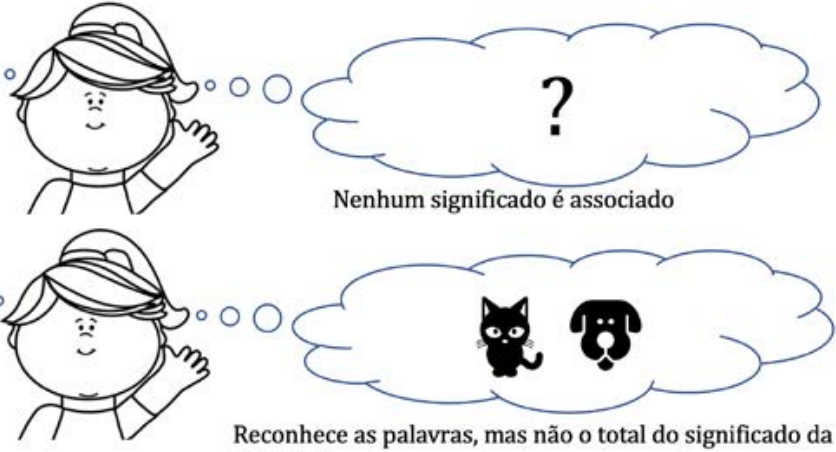

Reconhece as palavras, mas não o total do significado da sentença

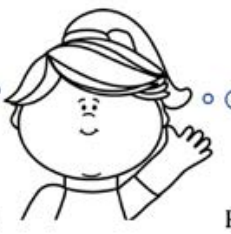

Representação plena do significado da sentença

Fonte: Adaptado de National Center on Improving Literacy ${ }^{3}$ 
No estágio não acurado, o leitor identifica letras, mas não consegue acessar a chave para a decodificação grafo-fonêmica (Figura 2). Logo, não há acesso ao significado, produzindo uma situação de não leitura ou de reconhecimento não acurado. No estágio acurado, a chave de decodificação grafo-fonêmica é ativada, via rota fonológica. $\mathrm{O}$ processo é acurado, mas por demandar esforço e memória de trabalho, o significado total da sentença se perde, é um leitor palavra por palavra, em um estágio acurado, mas não automático. O leitor fluente acessa a rota lexical, e acessa a representação plena do significado da sentença; é um leitor em um estágio acurado e automático. Assim, um fator importante que determina a fluência da leitura é a proporção de palavras em uma passagem que pode ser reconhecida como palavras visuais, pois este aspecto interfere na compreensão global do texto.

Leitura, então, envolve dois processos: o da compreensão linguística e o processo de decodificação. Essa é uma perspectiva conhecida como visão simples de leitura (simple view of reading), que embora tenha o rótulo de "simples", não é tão simples assim. Uma versão desse modelo pressupõe uma equação para o resultado da compreensão em leitura (CLe), que é o produto da decodificação (D) pela compreensão linguística (CLi): CLe = D x CLi. (GOUGH; TUNMER, 1986; HOOVER; GOUGH, 1990). Outra versão dessa perspectiva é o modelo de cordas de Scarborough (2009 [2001]), Figura 3, em que a leitura é uma corda, composta por vários fios entrelaçados, e se um dos fios dessa corda não está desenvolvido, enfraquece toda a corda. Além da compreensão da linguagem como um todo (vocabulário, gramática, processos inferenciais e conhecimento sobre tipos e gêneros), o reconhecimento de palavras é o outro componente necessário para a leitura fluente, mobilizando consciência fonológica, a descodificação e o reconhecimento visual das palavras (SCARBOROUGH, 2009; CUTTING; SCARBOROUGH, 2006).

Figura 3 - Modelo de cordas

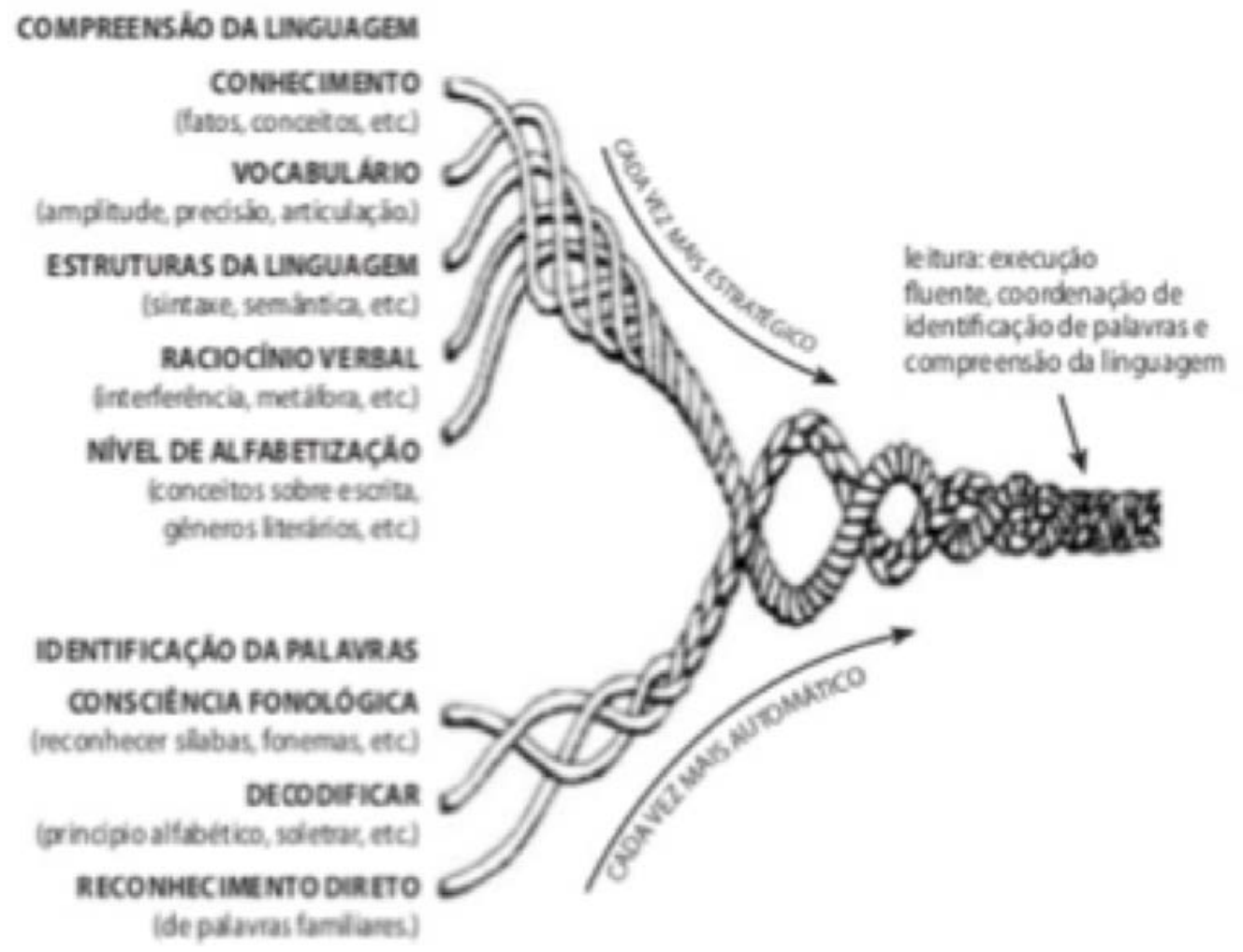

Fonte: Scarborough (2009, p. 23). 
mas sem ter essa habilidade, não se chega à compreensão. Ler não é só decodificar, é preciso compreender, mas para acessar o nivel da compreensão, é preciso decodificar automaticamente, assim como usar as estratégias adequadas para a eficiência da leitura, o que releva a importância do conhecimento linguístico: o conhecimento de gramática, que não pode ser entendida apenas como classificar palavras, mas explicitar conhecimentos sobre o processamento gramatical como estratégia para a compreensão linguística, tais como papéis temáticos, ordem, estrutura ativa/ passiva etc.). Essa é a base para o ensino reflexivo sobre gramática (VIEIRA, 2018).

O desempenho em leitura pode ser medido pela acurácia na decodificação grafo-fonêmica, a habilidade em usar relações de letras e sons para decodificar palavras novas; pela precisão na leitura de texto, a acurácia com que palavras individuais são identificadas no texto; pela fluência na leitura de textos, ou seja a velocidade de leitura em voz alta do texto inteiro; e pela compreensão de leitura, a precisão com que os sentidos são construidos durante a leitura.

E onde entra a Sociolinguística nisso tudo?

Como vimos, a leitura de um sistema de escrita alfabético pode ocorrer por meio de um processo de reconhecimento visual direto (rota lexical) ou por um processo envolvendo mediação fonológica (rota fonológica). No entanto, este processo não se estabelece por relação univoca nas correspondências grafo-fonêmicas. No português brasileiro, temos regras de desconversão transparentes, como em "bala", em que cada letra corresponde a um fonema. Em outros casos, temos regras não transparentes, como em "táxi", em que a letra "x" pode ter diferentes realizações fonêmicas, mas uma única nessa palavra é evocada, que só é ativada por experiência anterior. Essas relações são amplamente exploradas pela escola, e estão presentes em materiais didáticos e em avaliações oficiais de leitura, tais como a ANA e a Provinha Brasil (FREITAG, 2015).

Como deve ser lida a palavra "cenoura"? E "arroz"? A leitura de "cenoura" com ditongo, como faria um aprendiz que utiliza a rota fonológica para decodificar, não reflete o uso linguístico da comunidade de fala do português brasileiro: todo mundo fala monotonga "cenoura" na fala; o processo de monotongação é considerado um traço contínuo do português brasileiro (BORTONI-RICARDO, 2004), e a variante padrão é a realização monotongada (PAIVA, 1996). E na leitura? Devemos seguir regras de transparência grafo-fonêmica e ativar a rota fonológica para realizar o ditongo ou devemos ter memória visual da palavra e ativar a rota lexical, realizando a variante padrão na comunidade (no caso, a variante monotongada)?

A montongação de ditongos /ow/ é um processo estável em toda a comunidade linguística, sem interferências dialetais ou sociais. É diferente de "arroz", cuja leitura por meio de acesso à rota lexical pode variar em função da região: no sul do Brasil, a realização terá transparência grafo-fonêmica, mas em outras regiões, a realização será ditongada, sem transparência grafo-fonêmica.

Este é o tipo de informação que não se encontra em dicionários, e em algumas gramáticas, na parte de ortoepia, que trata de itens especificos e não previsiveis por regras ou principios do sistema alfabético da língua. Em relação aos ditongos, veja-se o que prescreve Bechara (2009):

Quanto aos ditongos, cumpre notar: ai, ei, e ou,
na pronúncia, devem guardar, na pronúncia
cultivada, sua integridade, não se exagerando
o valor do i ou do u, nem os eliminando, como o
faz a modalidade distensa: caixa, queijo, ouro. [...]
Normalmente ditongamos, pelo acréscimo de
um i, as vogais tônicas finais seguidas de um -z
ou -s. Assim não fazemos diferença entre pás,
pais e paz; mas e mais (BECHARA, 2009, p. 6o).

Nessa prescrição, o ditongo deve ser conservado em contextos que os falantes já não os realiza mais (exceto na modalidade "distensa"), e é inserido em um contexto não previsto pela ortografia, mas que ocorre na fala (e, por paralelismo, também na modalidade "tensa") de uma região do Brasil. Embora as instruções para a conversão grafo-fonêmica direcionem para a seleção da variante da comunidade, as orientações prescritivistas direcionam a escolha de variantes em função do prestígio. É o que Lemle (1978) chama de bidialetalismo funcional. E esse é um 
fato sociolinguístico que não pode ser ignorado.

Mas ditongação e monotongação são fenômenos que, na proposta de Bortoni-Ricardo (2004), são traços contínuos: presentes na fala de todos os brasileiros (ou de todos nas regiões em que ocorre, como é o caso da ditongação). Como lidar com os traços descontínuos: aqueles relacionados à fala de grupos e socialmente estigmatizados, como rotacismo, por exemplo? Há regularidade e previsibilidade na desconversão grafo-fonêmica (uma regra mais complexa, pois pressupõe a perda da transparência de "l" em ataques complexos), mas essa é uma regra que precisa ser explicitada para os grupos em cuja variedade linguistica o fenômeno ocorre. Ou, em casos mais especíicos, para o aluno que fala assim.

Assim como há todo o trabalho para a consciência fonológica para o aprendizado inicial da leitura, é necessário também o trabalho com a consciência sociolinguistica. Em termos descritivos, a Sociolinguística, desde os estudos pioneiros (LABOV, 1972b), classifica as variantes em função da sua apreciação social e consciência: também em contínuo, variantes que não estão no nivel da consciência dos falantes (indicadores), variantes que são sensiveis ao contexto (marcadores) e variantes cuja percepção é consciente e são objeto de manipulação (estereótipos). Embora a área da Sociolinguística no Brasil seja produtiva, e muito já tenha sido feito para a descrição de uma variedade brasileira do português, ainda temos vácuos descritos: fora dos grandes centros urbanos, fora das capitais, e grupos minorizados (FREITAG, 2016). Em termos práticos, para a leitura, a contribuição sociolinguística ainda é incipiente, mas que se faz amplamente necessária.

\section{Da fala para a leitura}

No campo da Sociolinguística brasileira, ainda são poucos os estudos que observam a variação na leitura em voz alta, em busca dos processos fonológicos que passam da fala para a leitura
(AQUINO, 2011; PINHEIRO et al., 2017; MACHADO, 2018). Esses estudos têm demonstrado uma associação entre processos variáveis classificados na fala como indicadores (caso da monotongação e apagamento de /R/ final em verbos, por exemplo) e transposição para a leitura em voz alta. Por outro lado, processos variáveis classificados como estereótipos (a palatalização progressiva, por exemplo) são barrados na leitura em voz alta. Outra constatação generalizada nesses estudos é de que a associação é desenvolvida progressivamente em função do avanço na escolarização. Em outra linha de abordagem, Miranda et al. (2017) identificam mudança na leitura em função da formalidade/ tipo de texto. Esses resultados indiciam o desenvolvimento da consciência sociolinguística, mais precisamente, da sensibilidade sociolinguística na escolha das variantes apropriadas ao contexto, e, ao mesmo tempo, sinalizam a automatização da decodificação: a monotongação e o apagamento do /R/ final de verbos na leitura em voz alta é evidência do acesso pela rota lexical, com a ativação da variante padrão na fala da comunidade. ${ }^{4} \mathrm{~A}$ automaticidade na decodificação libera demanda cognitiva para o processo de compreensão, e o leitor é proficiente. Por outro lado, ao realizar a decodificação por acesso à rota fonológica, seguindo regras de transparência grafo-fonêmica, a demanda cognitiva é toda direcionada para o processo de decodificação, e o leitor não atinge a compreensão. A transposição da variante de prestígio da fala espontânea para a leitura em voz alta sugere a automatização no processo de decodificação por via lexical, e consequente disponibilidade cognitiva para efeitos de processamento

Em um estudo que comparou o desempenho em compreensão e a ocorrência de traços variáveis da fala na leitura em voz alta, os alunos do $3^{\circ}$ ano do ensino fundamental que apresentaram as maiores taxas de realização de variáveis padrão da comunidade na tarefa de leitura em voz alta foram os que tiveram melhor desempenho em

\footnotetext{
4 A variante padrão na comunidade é aquela que tem maior frequência e não tem distinção de uso em função de perfis sociais, o que implica na não sensibilidade consciente desses traços pelos falantes, assumindo o comportamento de indicadores (LABOV, 1972). Esse é o critério para distinguir traços contínuos de descontinuos (BORTONI-RICARDO, 2004). Por esse critério, monotongação de /ow/, / ej/ e apagamento de /R/ em cada em verbos são variantes padrão no português brasileiro, na situação de fala (PAIVA, 1996; CALLOU: MORAES, LEITE, 1998).
} 
um teste de compreensão em leitura aos moldes da ANA (FREITAG; SÁ, 2019).

Também ao apresentar traços variáveis da fala que são considerados estigmatizados na leitura em voz alta, o leitor sinaliza o acesso à rota lexical, automatizando o processo de decodificação. 0 leitor que lê "planta" com rotacismo não pode ser considerado impreciso nem ter sua acurácia questionada. Ele ainda não desenvolveu a consciência sociolinguística relacionada ao contexto de ocorrência do traço. No estudo de Freitag e Sá (2019), traços descontínuos ocorreram somente nos estudantes que apresentaram leitura fluente, que foram os que atingiram os escores mais altos no teste de compreensão.

Assim, a memória visual da palavra, presente nos modelos de leitura, sofre efeitos de duas naturezas: os efeitos da variedade falada, que é distante da transparência do sistema ortográfico, e os efeitos de monitoramento social do contexto estilístico de atenção à fala e do contexto social da leitura. Por conta desses efeitos, o seu aprendizado é gradual. Identificar em que nivel do aprendizado está o aprendiz, ou que tipo de erro está sendo cometido, é importante para o direcionamento do processo. As pistas sociolinguísticas para a identificação dos estágios desse processo podem ser observadas na leitura em voz alta, na situação de sala de aula. Além de observar a realização do traço variável na situação de leitura, as operações de reparo podem sinalizar efeitos de monitoramento da leitura, denotando desenvolvimento de consciência sociolinguística.

Reparos na leitura em voz alta podem dar pistas da consciência sociolinguística do leitor, e da avaliação social do traço, na medida que traços social ou estilisticamente avaliados de modo negativos tendem a ser reparados ou corrigidos. Em um estudo de leitura em voz alta em um grupo de universitários, considerando segmentos-alvo quanto à realização e reparo, é possivel identificar padrões: processos altamente permeáveis à leitura, como apagamento do /R/ final e monotongação, com comportamento de indicadores; processos barrados pela leitura, como desnasalização, com comportamento de estereótipos (SOUZA; SILVA; ARAUJO Jr. 2020); processos conscientes (sensiveis à correção), como apagamento do /S/ final; e processos inconscientes (não sensiveis à correção), como redução do segmento /-ndo/(FREITAG, 2020).

Nesse último estudo, também foram verificados efeitos do contexto linguístico imediato quanto ao valor gramatical (morfêmico e não morfêmico), atuantes na fala, também transpassam para a leitura em voz alta (consciência morfológica). Isso sugere o efeito do processamento morfossintático e de sua automatização no custo de processamento na leitura: variantes morfossintáticas pouco frequentes demandam maior custo de processamento, e a combinação de variantes morfossintáticas pouco frequentes demanda maior capacidade de memória na decodificação, o que tem implicações na compreensão. Podemos considerar os reparos na leitura como evidências indiretas do custo do processamento, assim, observar os reparos na leitura em voz alta também dá pistas da fluência em leitura.

Assim, a partir das pistas observacionais da leitura em voz alta, considerando os achados da sociolinguística acerca da consciência e avaliação social de variantes linguísticas, do acesso às rotas na decodificação e a seleção das variantes da variedade linguística do falante, e procedimentos de reparo na leitura em voz alta, podemos estimar as habilidades dos leitores considerando os modelos de leitura que articulam processo de compreensão e reconhecimento de palavras, como visão simples de leitura, ou modelo de cordas (Figura 4). 
Figura 4 - Pistas da leitura em voz alta e habilidades de leitura a partir da visão simples de leitura

\section{Habilidade baixa}

Apresenta dificuldade para decodificar palavras desconhecidas e reconhece apenas palavras familiares.

Entende o significado de palavras e a estrutura gramatical na fala, mas pelas limitações da leitura, apresenta dificuldade no texto escrito

Processos de reconhecimento de palavra

\section{Habilidade muito baixa}

Apresenta muita dificuldade para reconhecer palavras escritas. Toda a demanda cognitiva é despendida na decodificação das letras

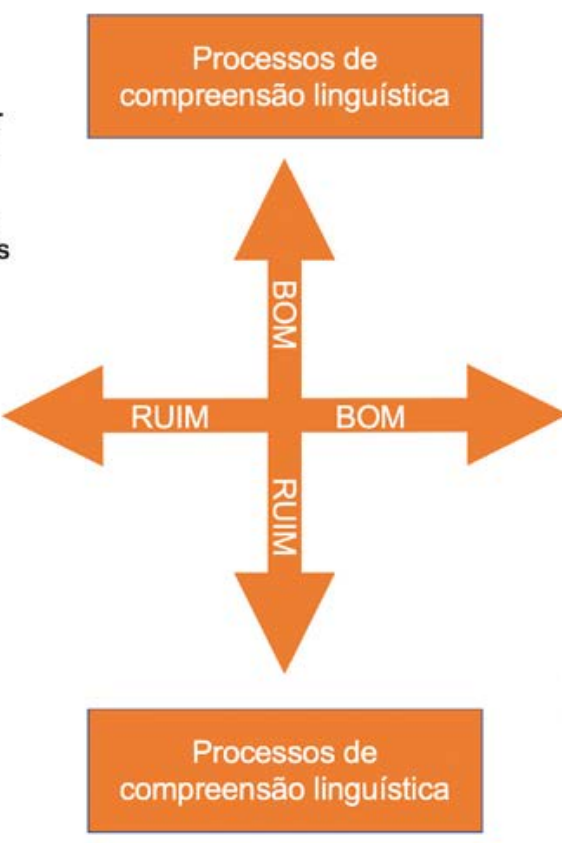

\section{Habilidade alta}

Pode reconhecer facilmente palavras desconhecidas escritas. Consegue compreender o sentido plenamente das palavras e usa a estrutura gramatical da fala para a compreensão do texto escrito

Processos de reconhecimento de palavra

\section{Habilidade baixa}

Pode reconhecer facilmente palavras desconhecidas escritas. Não consegue compreender o sentido plenamente das palavras; a estrutura gramatical da fala interfere na sua habilidade de compreensão do texto escrito

Fonte: Adaptado de Smith (2018, p. 66).

O leitor com bom domínio de processos de compreensão e com bom domínio no processo de reconhecimento de palavras é o leitor fluente, com consciência sociolinguística plenamente desenvolvida. Acessa as palavras conhecidas por rota lexical, ativando a variante de prestígio na fala da sua comunidade na leitura em voz alta; e quando diante de palavras desconhecidas, ativa a rota fonológica. Tem familiaridade com as construções gramaticais da escrita, por transposição das estruturas da fala. Este é o leitor modelo que a escola visa formar, que terá sucesso nas avaliações oficiais e que poderá exercer a sua cidadania. Ele existe, mas é minoria. É aquele leitor que já tem familiaridade com a cultura escrita desde antes de chegar à escola. É, via de regra, filho de pais escolarizados e residentes de regiões urbanas nos grandes centros. É aquele que o Programa Nacional do Livro Didático define como falante de uma das variedades urbanas de prestígio (BRASIL, 2013). Na leitura em voz alta, é o que chamaríamos de um leitor fluente, aquele que parece estar falando quando lê. Poucos e pontuais erros de desconversão, logo seguido por reparos.

O leitor com bom domínio dos processos de decodificação, mas com dificuldades na compre- ensão é o leitor que passou por um processo de alfabetização bem sucedido em termos de aprendizado das regras de conversão grafo-fonêmica, consegue acessar as palavras conhecidas por rota lexical, ativa a variante de prestígio na fala da sua comunidade na leitura em voz alta, e, diante de palavras desconhecidas, ativa a rota fonológica. No entanto, apresenta dificuldades de compreensão por conta de não lidar conscientemente o processamento gramatical. Ele não sabe o que fazer com as palavras: sujeito, predicado, papéis temáticos, voz ativa, voz passiva etc. são conceitos aos quais até teve acesso, mas não sabe como implementá-los na prática. Tem pouca familiaridade com a cultura escrita, não desenvolveu ainda consciência sociolinguística para as diferenças de modalidade/registro. Na sua leitura em voz alta, as palavras fluem com precisão, mas são estanques. É uma leitura palavra por palavra, com pausas em locais não previstos do ponto de vista gramatical. Esse aluno precisa ouvir leitura em voz alta, para perceber padrões sintáticos. Se os pais não leram para ele quando criança, é papel da escola cumprir essa demanda. Além disso, as aulas de gramática precisam ser produtivas e reflexivas, para que esse conhecimento esteja a serviço da 
compreensão da leitura. É essa a proposta dos três eixos de ensino de gramática (VIEIRA, 2018).

Por outro lado, o leitor com bom domínio dos processos de compreensão, por ter familiaridade com a cultura letrada, por ter tido experiências de ouvir leitura, é capaz de reconhecer estruturas da escrita. Mas, por conta de problemas no aprendizado inicial da leitura, uma alfabetização precária, sem automaticidade na decodificação, fica limitado ao uso da rota fonológica, para todos os contextos, inclusive para palavras familiares. Esse parece ser o leitor decodificador. Na sua leitura em voz alta, as decodificações serão sempre transparentes. Uma leitura "certinha" não quer dizer que seja uma leitura com acurácia, esse leitor gasta toda sua demanda cognitiva para a desconversão grafo-fonêmica, e não consegue passar ao nível da compreensão. Esse leitor precisa desenvolver a sensibilidade sociolinguística para o aprimoramento de suas habilidades; precisa ativar a rota lexical selecionando a variante de prestígio da fala de sua comunidade.

O leitor que enfrenta problema nos processos de reconhecimento de palavras, sem automaticidade na decodificação, e está distante da cultura letrada, enfrentando também dificuldade nos processos de compreensão linguística, é o leitor que Morais (2013) rotula de "fracassado". Na verdade, não é o leitor que é fracassado; é a escola que fracassou na formação desse leitor. E corrigir esse fracasso não é tarefa simples nem de responsabilidade de apenas um ente. Politicas públicas, as avaliações oficiais, os programas de ensino e as diretrizes na formação de professores para a leitura falharam. E essa é uma falha grande, sistematicamente apontada pelos resultados das avaliações oficiais em larga escala, em todo o sistema (ANA, Prova Brasil, Pisa, Enade).

A Sociolinguística brasileira tem ficado de fora dos debates sobre leitura; suas contribuições descritivas não têm sido consideradas. Evidência é o fato de ainda se insistir em pacotes educacionais genéricos para todo o Brasil, sem considerar os efeitos dialetais. Por outro lado, ainda pouco se sabe sobre a consciência sociolinguística e o processamento da variação linguística, campo de estudos ainda recente. Novas pesquisas nessa interface podem contribuir para o aprimoramento de políticas para a leitura.

\section{Considerações finais}

Leitores com sensibilidade sociolinguística são leitores proficientes. Pode parecer óbvio, mas o desempenho nas avaliações oficiais mostra que a realidade é muito distante. Sociolinguística a serviço da educação. Precisamos mobilizar resultados descritivos de estudos sociolinguísticos na formação de professores de lingua materna para a identificação de traços variáveis da fala que passam para a leitura e seu respectivo valor social. A formação sociolinguistica do professor de língua materna possibilita a identificação de pistas de fluência em leitura, a partir da observação da leitura em voz alta dos alunos, em situação de sala de aula. A partir da observação dessas pistas, o professor pode direcionar ações para o desenvolvimento e aprimoramento das habilidades de compreensão linguística e de reconhecimento de palavras, mesmo fora do periodo de aprendizado inicial.

Os problemas de leitura, se não enfrentados, persistem até na universidade, inclusive nos cursos de formação de professores de lingua materna! É uma situação de "trocar pneu com o carro andando". Difícil, mas necessário. E não impossivel.

\section{Referências}

ALMEIDA, Ayane Nararela Santos; FREITAG, Raquel Meister Ko. Análise do diagnóstico do desempenho em leitura: Provinha Brasil vs. fluência em leitura oral. Signo, Santa Cruz do Sul, RS, v. 37, n. 63, p. 98-110, 2012.

AQUINO, Maria de Fátima. Uma proposta de tipologia de "erros" de leitura: análise sociolinguistica e cognitiva. 2011. Tese (Doutorado em Linguística). Universidade Federal da Paraiba, João Pessoa, 2011.

BARETTA, Danielle; SANTOS, Thaise Azzolin; BORGES, Caroline Bernardes. Consciência linguistica no Ensino Fundamental: um estudo com foco no uso de estratégias de leitura. Letras de Hoje, Porto Alegre, v. 54, n. 2, p. 243-252, 2019. https://doi.org/10.15448/1984-7726.2019.2.32532

BARNITZ, John G. Black English and other dialects: Sociolinguistic implications for reading instruction. The Reading Teacher, Newark, DE, v. 33, n. 7. p. 779-786, 1980. 
BASSO, Fabiane Puntel et al. Instrumento de Avaliação da Fluência de Leitura Textual: da decodificação à compreensão de leitura. Letras de hoje, Porto Alegre, v. 54, n. 2, p. 146-153, 2019. https://doi.org/10.15448/19847726.2019.2.32519

BECHARA, Evanildo. Moderna gramática portuguesa. 37. ed. Rio de Janeiro: Nova Fronteira, 2009.

BORTONI-RICARDO, Stella Maris. Educação em lingua materna. São Paulo: Parábola, 2004.

BRASIL: Ministério da Educação. Secretaria de Educação Básica. Guia de livros didáticos: PNLD 2014: língua portuguesa: ensino fundamental: anos finais. 2013.

CALLOU, Dinah; MORAES, João; LEITE, Yonne. Apagamento do $R$ final no dialeto carioca: um estudo em tempo aparente e em tempo real. DELTA: Documentação de Estudos em Linguística Teórica e Aplicada, São Paulo, v. 14, n. SPE, 1998. https://doi.org/10.1590/ S0102-44501998000300006

COLTHEART, Max et al. DRC: a dual route cascaded model of visual word recognition and reading aloud. Psychological review, [s. l.], v. 108, n. 1, p. 204, 2001. https:// doi.org/10.1037/0033-295X.108.1.204

COLTHEART, Max et al. Models of reading aloud: Dual-route and parallel-distributed-processing approaches. Psychological review, [s. L.], v. 100, n. 4, p. 589, 1993. https://doi.org/10.1037/0033-295X.100.4.589

COLTHEART, Max; RASTLE, Kathleen. Serial processing in reading aloud: Evidence for dual-route models of reading. Journal of Experimental Psychology: human perception and performance, [s. L.], v. 20, n. 6, p. 1197. 1994. https://doi.org/10.1037/0096-1523.20.6.1197

COLTHEART, Max. Modelando a leitura: a abordagem da dupla rota. In: SNOWLING, Margareth; HULME, Charles (org.). A ciência da leitura. Porto Alegre: Penso, 2013. p. 24-41.

CORSO, Helena Vellinho; SALLES, Jerusa Fumagalli. Relação entre leitura de palavras isoladas e compreensão de leitura textual em crianças. Letras de Hoje, Porto Alegre, v. 44, n. 3, p. 28-35, 2009.

CORSO, Helena Vellinho; SPERB, Tânia Mara; SALLES, Jerusa Fumagalli de. Leitura de palavras e de texto em crianças: efeitos de série e tipo de escola, e dissociações de desempenhos. Letras de Hoje, Porto Alegre, v. 48, n. 1, p. 81-90, 2013.

CUTTING, Laurie E.; SCARBOROUGH, Hollis S. Prediction of reading comprehension: Relative contributions of word recognition, language proficiency, and other cognitive skills can depend on how comprehension is measured. Scientific studies of reading, [s. l.], v. 10, n. 3, p. 277299, 2006. https://doi.org/10.1207/s1532799xssr1003_5

EHRI, Linnea C. Grapheme: phoneme knowledge is essential for learning to read words in English. Word recognition in beginning literacy, [s. L.], v. 3, p. 40, 1998.

EHRI, Linnea C. Orthographic mapping in the acquisition of sight word reading, spelling memory, and vocabulary learning. Scientific Studies of Reading, Is. l.], v. 18, n. 1, p. 5-21, 2014. https://doi.org/10.1080/108 $\underline{88438.2013 .819356}$
EHRI, Linnea C. Phases of development in learning to read words by sight. Journal of research in reading, [s. l.], v. 18, n. 2, p. 116-125, 1995. https://doi.org/10.1111/j.1467-9817.1995.tbo0077.x

FLÔRES, Onici Claro. Leitura e consciência linguística. Letras de Hoje, Porto Alegre, v. 53, n. 1, p. 149-157, 2018. https://doi.org/10.15448/1984-7726.2018.1.28535

FREITAG, Raquel Meister Ko. Entre a teoria e a prática: a Provinha Brasil e o tratamento da variação linguística na alfabetização. Interfaces cientificas - Educação, Aracajú, SE, v. 3, n. 3, p. 43-54, 2015. https://doi.org/10.17564/ 2316-3828.2015v3n3p43-54

FREITAG, Raquel Meister Ko. Reparos na leitura em voz alta como pistas de consciência sociolinguistica. DELTA: Documentação de Estudos em Linguistica Teórica e Aplicada, São Paulo, v. 32, n. 1, p. 1-20, 2020. https:// doi.org/10.1590/1678-460x2020360206

FREITAG, Raquel Meister Ko.; SÁ, José Junior de Santana. Leitura em voz alta, variação linguística e o sucesso na aprendizagem inicial da leitura. Ilha do Desterro, Florianópolis, v. 72, n. 3, p. 41-62, 2019.

GOUGH, Philip B.; TUNMER, William E. Decoding, reading, and reading disability. Remedial and special education, [s. l.], v. 7. n. 1, p. 6-10, 1986. https://doi. org/10.1177/074193258600700104

HOOVER, Wesley A.; GOUGH, Philip B. The simple view of reading. Reading and writing, [s. L.], v. 2, n. 2, p. 127-160, 1990. https://doi.org/10.1007/BF00401799

$\mathrm{KIM}$, Young-Suk et al. Does growth rate in oral reading fluency matter in predicting reading comprehension achievement? Journal of Educational Psychology, [s. l.], v. 102, n. 3. p. 652, 2010. https://doi.org/10.1037/a0019643

KOMENO, Eliana Matiko et al. Velocidade de leitura e desempenho escolar na última série do ensino fundamental. Estudos de Psicologia (Campinas), Campinas, v. 32, n. 3, p. 437-447, 2015. https://doi.org/10.1590/ 0103-166X2015000300009

LABOV, William. Language in the inner city: Studies in the Black English vernacular. Pennsylvania: University of Pennsylvania Press, 1972a.

LABOV, William. Sociolinguistic patterns. Pennsylvania: University of Pennsylvania Press, 1972b.

LEMLE, Miriam. Heterogeneidade dialetal: um apelo à pesquisa. Tempo Brasileiro, [s. l.], v. 53, n. 4, p. 60-94, 1978.

MACHADO, Alessandra Pereira Gomes; FREITAG, Raquel Meister Ko. Pistas dos processos de decodificação que levam à compreensão da leitura. Letras de hoje, Porto Alegre, v. 54, n. 2, p. 132-145, 2019. https://doi. org/10.15448/1984-7726.2019.2.32509

MACHADO, Alessandra Pereira Gomes. Variação linguistica e leitura: fenômenos variáveis da fala na leitura em voz alta. A Cor das letras, Feira de Santana-BA, v. 19. n. 4, p. 196-218, 2018. https://doi.org/10.13102/ cl.v19i4Especial.2867

MIRANDA, Irma lunes, et al. A variação estilística em diferentes situações de leitura: variedade capixaba. Letras de Hoje, Porto Alegre, v. 52, n. 1, p. 68-76, 2017. 
MOLLICA, Maria Cecilia; LOUREIRO, Fernando. Aportes sociolinguisticos à alfabetização. In: RONCARATI, Claudia; ABRAÇADO, Jussara (org.). Português Brasileiro II: contato linguístico, heterogeneidade e história. Rio de Janeiro: EdUFF, 2008. p. 223-228.

MORAIS, José. Criar leitores - Para professores e educadores. Barueri: Manole, 2013.

NICHOLS, Patricia C. A sociolinguistic perspective on reading and black children. Language Arts, [s. l.], v. 54 , n. 2, p. 150-167, 1977.

PAIGE, David D., et al. Interpreting the relationships among prosody, automaticity, accuracy, and silent reading comprehension in secondary students. Journal of Literacy Research, [s. l.], v. 46, n. 2, p. 123-156, 2014. https://doi.org/10.1177/1086296X14535170

PAIVA, Maria da Conceição Auxiliadora. Supressão das semivogais nos ditongos decrescentes. In: OLIVEIRA e SILVA, Gisele M.; SCHERRE, Marta (org.). Padrões Sociolinguisticos: análise de fenômenos variáveis do português falado no Rio de Janeiro. Rio de Janeiro: Tempo Brasileiro, 1996. p. 217-236.

PIKULSKI, John J.; CHARD, David J. Fluency: Bridge between decoding and reading comprehension. The Reading Teacher, Newark, DE, v. 58, n. 6, p. 510-519, 2005. https://doi.org/10.1598/RT.58.6.2

PINHEIRO, Bruno Felipe Marques, et al. Processos fonológicos que passam da fala para a leitura. In: AZEVEDO, Isabel Cristina Michelan; ROIPHE, Alberto (org.). Leitura, escrita e literatura: interseções e convergências. São Cristóvão, EdUFS, 2017. p. 10-25.

RASINSKI, Timothy. Reading fluency instruction: Moving beyond accuracy, automaticity, and prosody. The Reading Teacher, Newark, DE, v. 59, n. 7, p. 704-706, 2006. https://doi.org/10.1598/RT.59.7.10

SAENGER, Paul. Space between words: The origins of silent reading. Stanford University Press, 1997.

SAMUELS, S. J. Reading Fluency: Its Development and Assessment. In: FARSTRUP, Alan E.; SAMUELS, S. Jay. (ed.). What Research Has to Say About Reading Instruction. 3. ${ }^{\text {rd }}$ ed. Newark. DE: International Reading Association, 2002. p. 166-183. https://doi. org/10.1598/0872071774.8

SCARBOROUGH, Hollis S. Connecting early language and literacy to later reading (dis) abilities: Evidence, theory, and practice. In: FLETCHER-CAMPBELL, Felicity; SOLER, Janet; REID, Gavin (org.). Approaching difficulties in literacy development: Assessment, pedagogy and programmes. Londres: Sage, 2009. p. 23-38.

SMITH, John E. Re-engineering national reading policy, pedagogy, and professional development: the case for a Simple View of Meaningful Reading. Teacher Education Advancement Network Journal, [s. l.], v. 10 , n. 2, p. 65-79, 2018.

SOARES, Magda. A reinvenção da alfabetização. Presença pedagógica, Belo Horizonte, v. 9, n. 52, p. 15-21, 2003.
SOUZA, Victor Renê Andrade; SILVA, Victória Laís; ARAUJO Jr., Mauro Monteiro. Da fala à leitura: variação linguística na leitura em voz alta de estudantes da Universidade Federal de Sergipe. Porto das Letras, Porto Nacional/TO, v. 6, n. 1, p. 1-29, 2020.

VIEIRA, Silvia Rodrigues. Gramática, variação e ensino: diagnose e propostas pedagógicas. São Paulo: Blucher, 2018.

WOLFRAM, Walt. Sociolinguistic alternatives in teaching reading to nonstandard speakers. Reading Research Quarterly, [s. l.], p. 9-33, 1970. https://doi. org/10.2307/747046

\section{Raquel Meister Ko. Freitag}

Doutora em Linguística pela Universidade Federal de Santa Catarina (UFSC), em Florianópolis, SC, Brasil; professora da Universidade Federal de Sergipe (UFS) em São Cristóvão, SE, Brasil. Bolsista de Produtividade em Pesquisa do CNPq e pesquisadora associada da Rede Nacional de Ciência para Educação (CpE).

\section{Endereço para correspondência}

Raquel Meister Ko. Freitag

Universidade Federal de Sergipe

Laboratório Multiusuário de Documentação Linguística (LAMID)

Cidade Universitária Prof. José Aloísio de Campos

Av. Marechal Rondon, s/n, Didática II, segundo andar Jardim Rosa Elze, 49100000

São Cristóvão, SE, Brasil 